\title{
Integrated analysis of programmed cell death ligand 1 expression reveals increased levels in high-grade glioma
}

\author{
Dorothee Hölzl ${ }^{1}$ - Georg Hutarew ${ }^{1} \cdot$ Barbara Zellinger $^{1} \cdot$ Hans U. Schlicker ${ }^{1} \cdot$ Christoph Schwartz $^{2} \cdot$ Peter A. Winkler $^{2}$. \\ Karl Sotlar $^{1} \cdot$ Theo F. J. Kraus $^{1}$ (D)
}

Received: 30 March 2021 / Accepted: 3 May 2021 / Published online: 8 May 2021

(c) The Author(s) 2021

\begin{abstract}
Purpose Gliomas are the most frequent primary brain tumors of adults. Despite intensive research, there are still no targeted therapies available. Here, we performed an integrated analysis of glioma and programmed cell death ligand 1 (PD-L1) in 90 samples including 58 glioma and 32 control brain tissues.

Methods To identify PD-L1 expression in glioma, we performed immunohistochemical analysis of PD-L1 tumor proportion score (TPS) using the clinically valid PD-L1 22C3 antibody on 90 samples including controls and WHO grade I-IV gliomas. Results We found that PD-L1 is highly expressed in a subfraction of glioma cells. Analysis of PD-L1 levels in different glioma subtypes revealed a strong intertumoral variation of PD-L1 protein. Furthermore, we correlated PD-L1 expression with molecular glioma hallmarks such as MGMT-promoter methylation, IDH1/2 mutations, TERT promoter mutations and LOH1p/19q.

Conclusion In summary, we found that PD-L1 is highly expressed in a subfraction of glioma, indicating PD-L1 as a potential new marker in glioma assessment opening up novel therapeutic approaches.
\end{abstract}

Keywords Glioma $\cdot$ Glioblastoma $\cdot$ Programmed cell death ligand $1 \cdot$ PD-L1 $\cdot$ Molecularly targeted therapy

\section{Introduction}

Gliomas represent the most frequent primary brain tumors of adults (Louis et al. 2016a). According to the guidelines of the World Health Organization (WHO) for classification of brain tumors, gliomas are assigned to WHO-Grade I-IV tumors representing the degree of aggressiveness (Louis et al. 2016a).

While WHO-Grade I pilocytic astrocytomas (PA) are slow growing gliomas with a good prognosis, WHO-Grade IV glioblastomas (GBM) are highly malignant and diffusely infiltrating brain tumors with a very unfavorable outcome (Louis et al. 2016a). With a reported annual incidence of 3-4

Theo F. J. Kraus

t.kraus@salk.at

1 Institute of Pathology, University Hospital Salzburg, Paracelsus Medical University, Müllner Hauptstr. 48, 5020 Salzburg, Austria

2 Department of Neurosurgery, University Hospital Salzburg, Paracelsus Medical University, Ignatz-Harrer-Str. 79, 5020 Salzburg, Austria cases per 100,000 population in the western world, GBMs are also the most frequently diagnosed brain tumors in adult patients (Louis et al. 2016a). The highly aggressive clinical behavior of GBMs is also reflected by the histological appearance: They show a high mitotic count, microvascular proliferation and necrosis (Louis et al. 2016a).

For advanced glioma stratification, the 2016 WHO Classification for Central Nervous System (CNS) Tumors integrated molecular genetic findings for advanced tumor classification: (Louis et al. 2016a). Key findings are mutations of the IDHI and IDH2 (Isocitrate Dehydrogenase), H3F3A (Histone H3 Family 3A), HISTIH3B and HIST1H3C genes, TERT (Telomerase Reverse Transcriptase) promotor mutations as well as combined chromosomal losses of chromosome $1 \mathrm{p}$ and 19q (loss of heterozygosity, LOH) (Louis et al. 2016a). Integrating these molecular findings with histology, there is a severe advance in the prediction of patient outcome (Louis et al. 2007, 2016a, b).

With regard to therapeutic targets, the analysis of the O6-methylguanin-DNA-methyltransferase (MGMT) promotor is of crucial importance (Hegi et al. 2008, 2009; Kaina et al. 2007). The MGMT protein is associated with DNA 
repair mechanisms, and epigenetic silencing of MGMT transcription by promoter hypermethylation compromises DNA repair mechanisms. Thus, a hypermethylated tumor promoter status has been found to associate with significantly improved survival in patients receiving combined and adjuvant radio-chemotherapy with temozolomide according to the EORTC/NCIC protocol (Hegi et al. 2005). Despite intensive research there is still no targeted therapy available and even by applying temozolomide, the patient outcome is still very unfavorable (Hegi et al. 2004, 2005, 2008, 2012; Hau et al. 2007).

Programmed Cell Death Ligand 1 (PD-L1) is a key player in triggering immune response in human cancers (Campesato et al. 2015; Gatalica et al. 2014; Ohaegbulam et al. 2015). Thereby, PD-L1 interacts with PD-1 (Programmed Cell Death 1) and inhibits immune response by induction of IL-10 (Interleukin) in monocytes (Said et al. 2010). In many tumors, there is an overexpression of PD-L1 that represents a druggable target (Sun et al. 2018; Honda et al. 2017; Kataoka and Ogawa 2016; Kataoka et al. 2016; Isaacsson Velho and Antonarakis 2018; Fan et al. 2019). In lung, breast, gastrointestinal and many other cancers with PD-L1 overexpression showed good response with PD-L1 inhibitors (Reck et al. 2016; Li et al. 2016; Fujita et al. 2015).

However, there is no reliable data available on PD-L1 in glioma with regard to morphological subtypes and genetic profiles. Here, we analyzed PD-L1 expression in 90 different tissue specimens. Thereby, we included 58 glioma samples of WHO Grades I-IV and 32 control brain tissue specimens (16 frontal cortex and 16 frontal white matter samples). Furthermore, we performed integrated analysis of PD-L1 expression and molecular hallmarks of analyzed gliomas.

\section{Materials and methods}

\section{Tissue collection}

We analyzed 90 anonymized tissue samples including 58 glioma and 32 control brains samples. Gliomas were allocated to WHO Grades I to IV and an integrated molecular profiling was performed according to the 2016 WHO classification of CNS tumors (Louis et al. 2016a). All samples were formalin-fixed and paraffin-embedded (FFPE) and stored in the tissue collection of the University Institute of Pathology of the University Hospital Salzburg. Control samples included 16 frontal cortex and 16 frontal white matter samples of post-mortem brains that were formalin-fixed and paraffin-embedded and stored in the tissue collection of the University Institute of Pathology of the University Hospital Salzburg. Details on glioma and control samples including PD-L1 status can be found in Tables 1 and 2.

\section{Molecular genetic characterization of gliomas}

Molecular genetic analysis of glioma samples was performed as previously described (Kraus et al. 2020). In brief, DNA extraction for molecular pathological analysis was performed of microscopically identified representative tumor tissues with at least $90 \%$ of viable tumor cells applying the Maxwell system (Promega) according to the manufacturer's instructions. $I D H I$ and $I D H 2$ and $B R A F$ hot spot mutations were analyzed applying the AmpliSeq for Illumina Cancer Hotspot Panel v2 (Illumina) on an Illumina MiniSeq next generation sequencing device (Illumina) according to the manufacturer's protocols. Hot spot loci of TERT promoter, H3F3A, HISTIH3B and HISTIH3C genes were analyzed by Sanger sequencing as described previously (Kraus et al. 2020). MGMT promotor methylation was assessed by methylation specific PCR (MSP) and bisulfite sequencing (Kraus et al. 2015a, b). Assessment of $1 \mathrm{p} / 19 \mathrm{q}$ status was performed by Fluorescence in situ hybridization (FISH) applying ZytoLight 1p/1q and $19 q / 19 p$ probe sets (ZytoVision) following the manufacturer's protocols. According to the guidelines of the current WHO classification, 1p/19q status was assessed in all $I D H$ mutated glioma, since loss of $1 \mathrm{p}$ and $19 \mathrm{q}$ is only occurring in gliomas harboring $I D H$ mutations (Louis et al. 2016a).

\section{Immunohistochemical analysis}

Routine immunohistochemistry performed on glioma samples included antibodies against GFAP, Ki67 and PHH3. PD-L1 expression was assessed applying the PD-L1 22C3 antibody (M3653 antibody kit, Dabo). Quantification of PD-L1 levels were performed by DH, TFJK and GH using the tumor proportion score (TPS) (Li et al. 2017; Neuman et al. 2016; Roge et al. 2017). All immunohistochemical stains were performed on a Ventana BenchMark Ultra device (Roche) according to the manufacturer's protocols.

\section{Computational data analysis}

Statistical analysis was performed using Prism 9 (GraphPad) software suite. As statistical tests, we applied $t$ test and one-way ANOVA with uncorrected Fisher's Test. Statistical significance was assumed for $p$ values $<0.05$. 


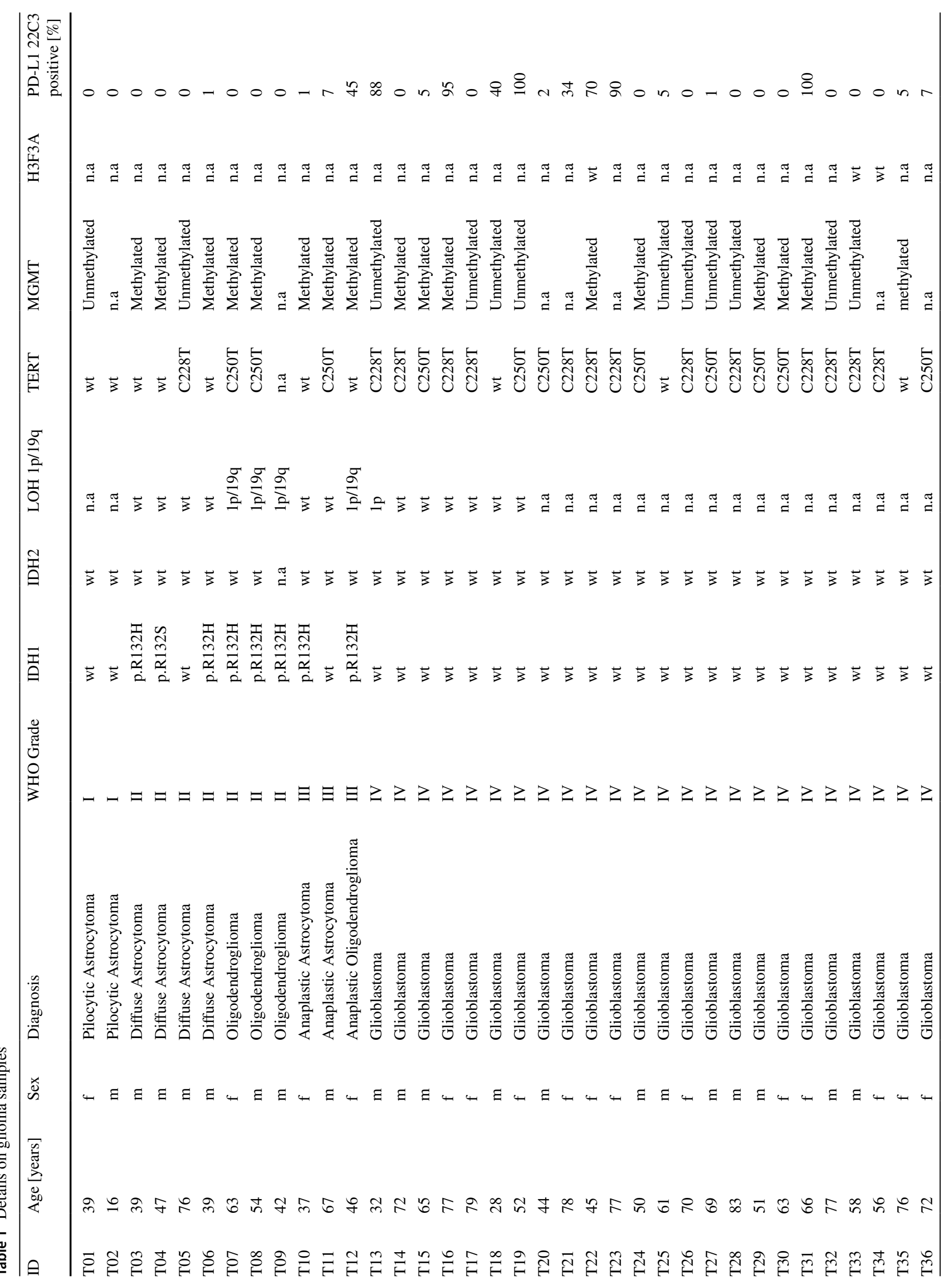




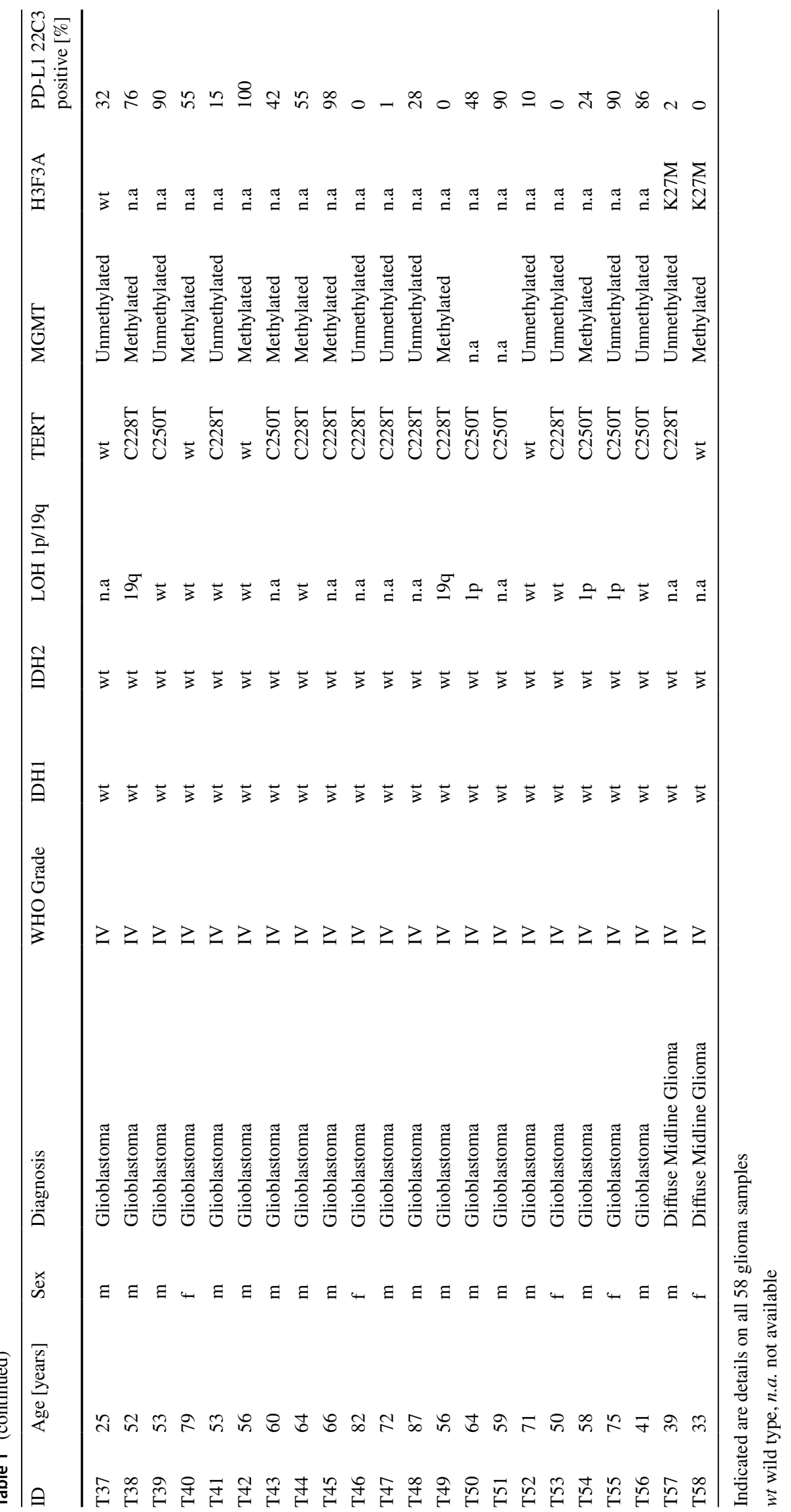


Table 2 Details on control samples

\begin{tabular}{|c|c|c|c|c|}
\hline ID & Age [years] & Sex & Region & $\begin{array}{l}\text { PD-L1 22C3 } \\
\text { positive [\%] }\end{array}$ \\
\hline $\mathrm{C} 01$ & 95 & $\mathrm{~m}$ & Frontal Cortex & 0 \\
\hline $\mathrm{C} 02$ & 56 & $\mathrm{~m}$ & Frontal Cortex & 0 \\
\hline $\mathrm{C} 03$ & 62 & $\mathrm{~m}$ & Frontal Cortex & 0 \\
\hline $\mathrm{C} 04$ & 65 & $\mathrm{f}$ & Frontal Cortex & 0 \\
\hline $\mathrm{C} 05$ & 92 & $\mathrm{f}$ & Frontal Cortex & 0 \\
\hline $\mathrm{C} 06$ & 75 & $\mathrm{f}$ & Frontal Cortex & 0 \\
\hline $\mathrm{C} 07$ & 75 & $\mathrm{f}$ & Frontal Cortex & 0 \\
\hline $\mathrm{C} 08$ & 87 & $\mathrm{f}$ & Frontal Cortex & 0 \\
\hline $\mathrm{C} 09$ & 54 & $\mathrm{f}$ & Frontal Cortex & 0 \\
\hline $\mathrm{C} 10$ & 67 & $\mathrm{f}$ & Frontal Cortex & 0 \\
\hline $\mathrm{C} 11$ & 79 & $\mathrm{f}$ & Frontal Cortex & 0 \\
\hline $\mathrm{C} 12$ & 69 & $\mathrm{f}$ & Frontal Cortex & 0 \\
\hline C13 & 89 & $\mathrm{f}$ & Frontal Cortex & 0 \\
\hline $\mathrm{C} 14$ & 52 & $\mathrm{~m}$ & Frontal Cortex & 0 \\
\hline $\mathrm{C} 15$ & 59 & $\mathrm{~m}$ & Frontal Cortex & 0 \\
\hline C16 & 54 & $\mathrm{~m}$ & Frontal Cortex & 0 \\
\hline W01 & 95 & $\mathrm{~m}$ & Frontal White Matter & 0 \\
\hline W02 & 56 & $\mathrm{~m}$ & Frontal White Matter & 1 \\
\hline W03 & 62 & $\mathrm{~m}$ & Frontal White Matter & 0 \\
\hline W04 & 65 & $\mathrm{f}$ & Frontal White Matter & 0 \\
\hline W05 & 92 & $\mathrm{f}$ & Frontal White Matter & 0 \\
\hline W06 & 75 & $\mathrm{f}$ & Frontal White Matter & 0 \\
\hline W07 & 75 & $\mathrm{f}$ & Frontal White Matter & 0 \\
\hline W08 & 87 & $\mathrm{f}$ & Frontal White Matter & 0 \\
\hline W09 & 54 & $\mathrm{f}$ & Frontal White Matter & 0 \\
\hline W10 & 67 & $\mathrm{f}$ & Frontal White Matter & 0 \\
\hline W11 & 79 & $\mathrm{f}$ & Frontal White Matter & 0 \\
\hline W12 & 69 & $\mathrm{f}$ & Frontal White Matter & 0 \\
\hline W13 & 89 & $\mathrm{f}$ & Frontal White Matter & 0 \\
\hline W14 & 52 & $\mathrm{~m}$ & Frontal White Matter & 0 \\
\hline W15 & 59 & $\mathrm{~m}$ & Frontal White Matter & 0 \\
\hline W16 & 54 & $\mathrm{~m}$ & Frontal White Matter & 1 \\
\hline
\end{tabular}

Indicated are details on all 32 control samples

\section{Results}

\section{PD-L1 is expressed in human gliomas}

To evaluate the significance of PD-L1 expression in gliomas, we used the PD-L1 22C3 antibody and performed immunohistochemical analysis in 90 tissue samples. These samples include 58 gliomas of WHO grades I, II, III and IV and 32 control brain samples including cortex and white matter regions. We found that there was no PD-L1 expression in control tissue, i.e., cortex $(n=16$, Fig. 1a, b) and white matter ( $n=16$, Fig. 1c, d). In gliomas, we found uneven PD-L1 expression. Low grade gliomas consisting of WHO grade I pilocytic astrocytomas $(n=2$, Fig. 1e, f) and WHO grade II diffuse gliomas ( $n=7$, Fig. $1 \mathrm{~g}, \mathrm{~h})$ did not show noteworthy PD-L1 expression. High grade gliomas consisting of WHO grade III anaplastic gliomas $(n=3$, Fig. $1 \mathrm{i}, \mathrm{j})$ and WHO grade IV glioma $(n=46$, Fig. 1k, 1), showed intermediate to high PD-L1 expression. PD-L1 tumor proportion scores (TPS) of all 90 analyzed samples can be found in Fig. $1 \mathrm{~m}$.

\section{PD-L1 is significantly overexpressed in high grade gliomas}

A detailed analysis of PD-L1 expression in all 90 tissues specimen revealed significant overexpression of PD-L1 in glioma compared with healthy brain tissue: There was a statistically significant overexpression in glioma compared to cortex $(p<0.01$, Fig. $2 \mathrm{a})$ and white matter $(p<0.01$, Fig. 2a). Analyzing PD-L1 expression and WHO grade confirmed high PD-L1 expression in high grade gliomas with a significant overexpression in WHO grade IV glioblastomas ( $p<0.05$, Fig. $2 \mathrm{~b}$ ). A detailed analysis of PD-L1 expression in glioma showed that $24 \%$ of all glioma showed TPS of $\geq 50 \%, 14 \%$ showed TPS of $25-50 \%$, $10 \%$ showed TPS of $10-25 \%, 4 \%$ showed TPS of $5-10 \%$, $10 \%$ showed TPS of $1-5 \%$ and $38 \%$ showed TPS of $<1 \%$ (Fig. 2c).

\section{Integrated analysis of PD-L1 expression and molecular glioma hallmarks}

Since gliomas show distinct molecular hallmarks, we next performed an integrated analysis of PD-L1 TPS and molecular genetic status: IDH mutation, TERT promoter mutation, MGMT promoter methylation and loss of heterozygosity of $1 \mathrm{p}$ and $19 \mathrm{q}(\mathrm{LOH} 1 \mathrm{p} / 19 \mathrm{q})$. Interestingly, $I D H$ wild-type glioma $(n=46)$ showed a significant higher expression of PD-L1 compared with $I D H$ mutated gliomas ( $n=8, p<0.05$, Fig. 3a). Due to the different biological backgrounds (Louis et al. 2016a) of pilocytic astrocytomas and $H 3 F 3 A$ mutated diffuse midline gliomas, these samples were excluded from $I D H$ analysis. In case of TERT promoter mutation, TERT mutated gliomas $(n=42)$ showed higher PD-L1 expression compared with TERT wild-type gliomas $(n=5, p>0.05)$ (Fig. 3b). An analysis of loss of heterozygosity of $1 p$ and $19 q(\mathrm{LOH} 1 \mathrm{p} / 19 \mathrm{q})$ showed higher PD-L1 expression in gliomas without LOH $1 \mathrm{p} / 19 \mathrm{q}(n=54)$ compared to LOH $1 \mathrm{p} / 19 \mathrm{q}$ aberrant gliomas ( $n=4, p>0.05$ (Fig. 3c). Analysis of PD-L1 expression and MGMT promoter methylation showed higher PD-L1 expression in MGMT methylated glioma $(n=26)$ compared to MGMT unmethylated glioma $(n=23, p>0.05)$ (Fig. 3d). 

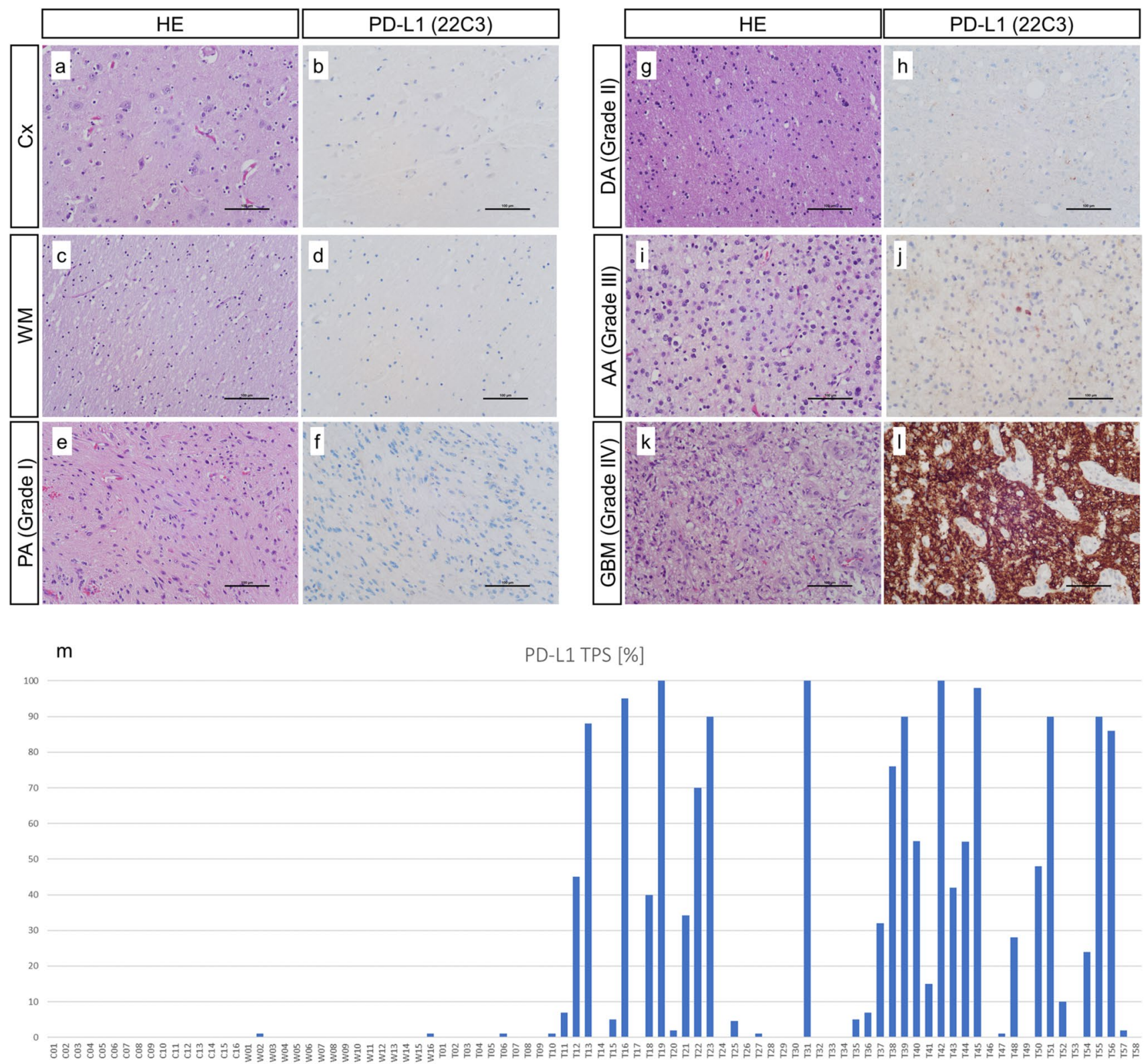

Cortex

White Matter

$\mathrm{III}^{\circ}$

$\mathrm{IV}^{\circ}$

Fig. 1 PD-L1 expression in healthy brain tissue and glioma. Analysis of 90 tissue samples showed no PD-L1 expression in healthy cortex $(\mathbf{a}, \mathbf{b})$ and white matter regions $(\mathbf{c}, \mathbf{d})$. There was no noteworthy PD-L1 expression in low grade glioma, i.e., WHO grade I pilocytic astrocytoma $(\mathbf{e}, \mathbf{f})$ and diffuse astrocytoma $(\mathbf{g}, \mathbf{h})$. In high grade glioma there was an uneven PD-L1 expression with strong intertumoral

\section{Discussion}

Despite intensive research, there are still no curative therapies available for GBM patients (Louis et al. 2016a). One milestone in glioblastoma therapy was the discovery of the connection between methylation of the MGMT promotor (Hegi et al. 2008, 2009; Kaina et al. 2007) and tumor heterogeneity in WHO grade III anaplastic astrocytoma (i, j) and glioblastoma $(\mathbf{k}, \mathbf{l})$. Distinct PD-L1 TPS scores of all 90 analyzed samples is presented in m. $C X$ cortex, $W M$ white matter, $P A$ pilocytic astrocytoma, $D A$ diffuse astrocytoma, $A A$ anaplastic astrocytoma, $G B M$ glioblastoma. a-l Scale bar: $100 \mu \mathrm{m}$

response to chemotherapy using temozolomide in 2005 (Hegi et al. 2005). However, since then there have not been any significant advances in glioblastoma therapy.

In anti-tumor therapy, PD-L1 is already a key player in personalized medicine, since it represents a druggable target (Sun et al. 2018; Honda et al. 2017; Kataoka and Ogawa 2016; Kataoka et al. 2016; Isaacsson Velho and Antonarakis 
a

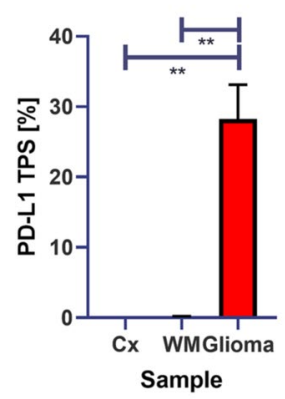

C

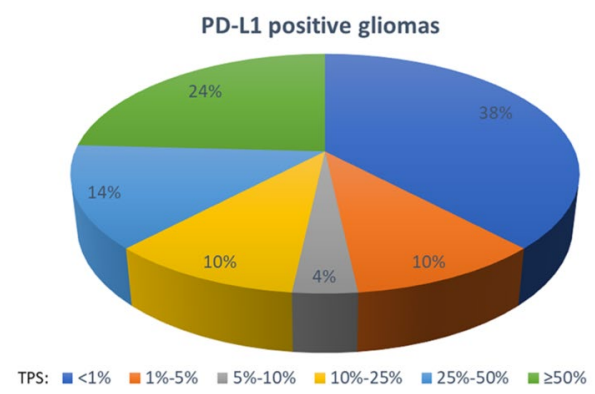

Fig. 2 Statistical analysis of PD-L1 expression. Statistical analysis of PD-L1 expression showed significant overexpression of PD-L1 in glioma compared with healthy cortex (a) and white matter (b). Analysis of WHO grade I, II, III and IV glioma showed significant overexpression in high grade glioblastoma compared with low grade diffuse glioma. Analysis of individual TPS showed PD-L1 expression in glioma showed TPS of $\geq 50 \%$ in $27 \%$ of gliomas, TPS of $25-50 \%$ in $12 \%$ of gliomas, TPS of $10-25 \%$ in $10 \%$ of gliomas, TPS of $5-10 \%$ in $2 \%$ of gliomas, TPS of $1-5 \%$ in $9 \%$ of gliomas, and TPS of $<1 \%$ in $40 \%$ of gliomas (c). a, b Indicated are mean and SEM. ${ }^{*} p<0.05, * * p<0.01$

2018; Fan et al. 2019). In many tumors, such as lung, breast, gastrointestinal PD-L1 inhibitors show great advances in patient treatment (Reck et al. 2016; Li et al. 2016; Fujita et al. 2015). Thereby, the expression profile of PD-L1 is assessed immunohistochemically.

Here, we assessed PD-L1 expression using the tumor proportion score (TPS), i.e., the percentage of PD-L1 positive tumor cells compared with all vital tumor cells ( $\mathrm{Li}$ et al. 2017; Neuman et al. 2016; Roge et al. 2017) to assess PD-L1 expression in gliomas, and thus to evaluate the feasibility of PD-L1 inhibitors in highly aggressive brain tumors.

Our analysis of PD-L1 expression revealed that there are high PD-L1 expression levels in high grade glioma with a high interindividual variation (Fig. 1). While control cortex and white matter tissues showed mean PD-L1 TPS of $0 \%$, gliomas showed significantly increased PD-L1 TPS with a mean of $28 \%$ in all 58 gliomas (Fig. 2a). A further subgroup analysis of different WHO grades showed that PD-L1 expression can be found predominantly in high grade gliomas with mean amounts of $18 \%$ positive tumor cells in WHO grade III gliomas and 34\% positive tumor cell in WHO grade IV glioblastomas, respective (Fig. 2b). Furthermore, we performed integrated analysis of molecular key hallmarks in glioma (IDH, TERT, MGMT methylation) and PD-L1 expression. Interestingly, we found significantly higher PD-L1 expression in $I D H$ wild-type glioma (mean amounts of $32 \%$ ) compared with IDH mutated gliomas (mean amounts of $6 \%, p<0.05$, Fig. 3a). In terms of TERT, we found higher PD-L1 expression in TERT mutated glioma (mean amounts of 32\%) compared with TERT wild-type glioma (mean amounts of $20 \%, p>0.05$, Fig. $3 b$ ). An analysis of loss of heterozygosity of $1 \mathrm{p}$ and $19 \mathrm{q}(\mathrm{LOH} 1 \mathrm{p} / 19 \mathrm{q})$ showed higher PD-L1 expression in gliomas without LOH $1 \mathrm{p} / 19 \mathrm{q}$ (mean amounts of $30 \%$ ) compared with $\mathrm{LOH} 1 \mathrm{p} / 19 \mathrm{q}$ aberrant gliomas (mean amounts of $11 \%, p>0.05$, Fig. 3c). Analysis of MGMT promoter methylation revealed higher PD-L1 expression in MGMT methylated glioma (mean a

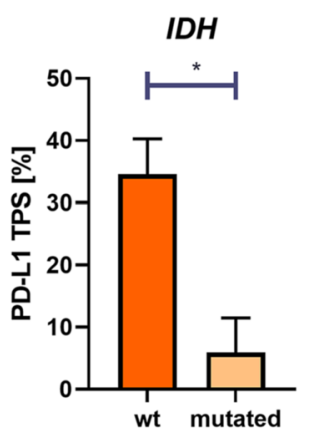

b

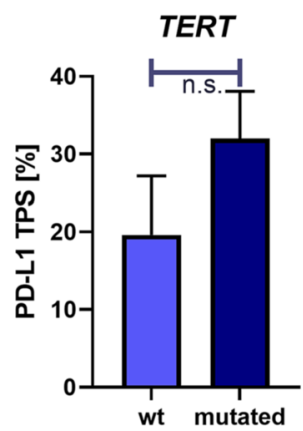

Fig. 3 Integrated analysis of PD-L1 expression and molecular genetic hallmarks of glioma. Analysis of PD-L1 expression and IDH status showed higher expression of PD-L1 in IDH wild type compared to IDH R132H mutated glioma (a). In case of TERT promoter mutation there was higher PD-L1 expression in TERT C228T and C250T

C
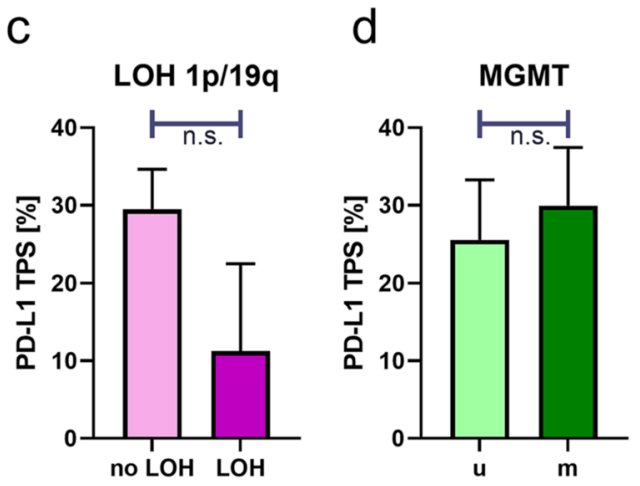

mutated glioma (b). Analysis of LOH 1p/19q showed higher expression of PD-L1 in gliomas without LOH 1p/19q (d). Analysis of MGMT promoter methylation showed higher expression of PD-L1 in methylated glioma (c). Indicated are mean and SEM. $m$ methylated, $u$ unmethylated; $n . s$. not significant $(p>0.05),{ }^{*} p<0.05$ 
amounts of 30\%) compared with MGMT unmethylated glioma (mean amounts of 26\%, Fig. 3d).

Considering the gliomagenesis and aggressiveness of glioma, Louis et al. (2016a) these findings are of high therapeutic impact: while $I D H$ mutation is a key pathway in gliomagenesis of WHO grade II and III gliomas and secondarily progressed WHO grade IV glioblastomas, IDH wild-type is a typical hallmark of primary WHO grade IV glioblastomas. Thus, the finding of high PD-L1 expression in $I D H$ wildtype primary glioblastomas is of severe clinical importance opening new therapeutic approaches in therapy of highly aggressive glioblastoma. Vice versa to $I D H$ mutations, TERT mutations are predominantly present in glioblastoma. Thus, the result of high PD-L1 expression in TERT mutated gliomas may also be of high clinical importance for therapy of highly aggressive glioblastomas.

Since the importance of PD-L1 has already been established as personalized medicine target in other tumor entities (Sun et al. 2018; Honda et al. 2017; Kataoka and Ogawa 2016; Kataoka et al. 2016; Isaacsson Velho and Antonarakis 2018; Fan et al. 2019; Reck et al. 2016; Li et al. 2016; Fujita et al. 2015) our findings in glioma may also open new therapeutic approaches in future brain tumor therapy. Thereby, our results are well in line with published data: Nduom et al. found that PD-L1 expression can be found in a subfraction of glioblastoma (Nduom et al. 2016). Thereby high PD-L1 expression is correlated with worse outcome (Nduom et al. 2016). Heiland et al. also report of high PD-L1 expression in glioblastoma with predominance of IDH wild-type glioblastomas (Heiland et al. 2017). Berghoff et al. analyzed PD-L1 expression and tumor infiltrating lymphocytes (TIL) in diffuse glioma and found that high PD-L1 expression and prominent TILs are predominantly present in $I D H$ wild-type glioma compared with $I D H$ mutant glioma (Berghoff et al. 2017). Hao et al. performed a meta-analysis of PD-L1 expression in glioblastoma and also confirmed that high PD-L1 expression can be found predominantly in glioblastoma with unfavorable outcome (Hao et al. 2020). This finding is well in accordance with our results demonstrating that highly aggressive $I D H$ wild-type gliomas show higher PD-L1 expression. In contrast to previous studies, Nduom et al. (2016), Heiland et al. (2017), Hao et al. (2020) we performed PD-L1 expression using the widely accepted and clinically applicable PD-L1 22C3 clone (M3653 antibody kit, Dako) and the tumor proportion score (TPS). Thus, our approach using the PD-L1 22C3 antibody and TPS to evaluate PD-L1 expression opens the way for monoclonal antibody therapies such as prembolizumab in a clinical setting (Ilie et al. 2017). However, the significance of this study is limited due to the low number of cases in distinct subgroups of glioma, such as oligodendroglioma and diffuse midline glioma. Thus, further studies with an increased number of cases will be needed to validate these results. A further limitation of this study is that only a limited set of molecular parameters was assessed, e.g., there was no molecular assessment of the BRAF status in pilocytic astrocytomas. Furthermore, there is one case of diffuse astrocytoma with $I D H$ wild-type status and TERT mutation included in this study. This is a very untypical genotype-phenotype combination and there should be further molecular assessment according to the cIMPACT guidelines (Louis et al. 2020; Gonzalez Castro and Wesseling 2021) including copy number profiling (CNP) to further characterize such cases and to assess, if the underlying biology is that of glioblastoma $I D H$ wild type.

In summary, our findings demonstrate the significance of PD-L1 testing in glioma enabling new individualized strategies for molecularly targeted therapy in highly aggressive brain tumors.

Acknowledgements We would like to thank the members of the histology, immunohistochemistry and molecular pathology facilities at the Institute of Pathology for their support in conducting this study.

Authors' contributions Conceptualization: TFJK and KS; methodology: TFJK, KS, DH, GH, BZ, HUS, CS, PAW; software: TFJK, DH; validation: $\mathrm{DH}$; formal analysis: $\mathrm{DH}, \mathrm{TFJK}, \mathrm{GH}$; investigation: $\mathrm{DH}$; resources: KS; data curation: DH, TFJK; draft preparation: TFJK; draft review and editing: TFJK, DH, KS, GH, CS, PAW; visualization: DH, TFJK; supervision: KS, TFJK; project administration: KS, TFJK All authors have read and agreed to the submitted version of the manuscript

Funding Open access funding provided by Paracelsus Medical University.

Data availability Details on data can be found in Tables 1 and 2, further information on the datasets used and/or analyzed during the current study are available from the corresponding author on reasonable request.

\section{Declarations}

Conflicts of interest/Competing interests None declared.

Ethical approval All procedures performed in studies were in accordance with the ethical standards of the institutional and/or national research committee and with the 1964 Helsinki declaration and its later amendments or comparable ethical standards.

Open Access This article is licensed under a Creative Commons Attribution 4.0 International License, which permits use, sharing, adaptation, distribution and reproduction in any medium or format, as long as you give appropriate credit to the original author(s) and the source, provide a link to the Creative Commons licence, and indicate if changes were made. The images or other third party material in this article are included in the article's Creative Commons licence, unless indicated otherwise in a credit line to the material. If material is not included in the article's Creative Commons licence and your intended use is not permitted by statutory regulation or exceeds the permitted use, you will need to obtain permission directly from the copyright holder. To view a copy of this licence, visit http://creativecommons.org/licenses/by/4.0/. 


\section{References}

Berghoff AS, Kiesel B, Widhalm G, Wilhelm D, Rajky O, Kurscheid S, Kresl P, Wohrer A, Marosi C, Hegi ME, Preusser M (2017) Correlation of immune phenotype with IDH mutation in diffuse glioma. Neuro Oncol 19(11):1460-1468. https://doi.org/10.1093/ neuonc/nox054

Campesato LF, Barroso-Sousa R, Jimenez L, Correa BR, Sabbaga J, Hoff PM, Reis LF, Galante PA, Camargo AA (2015) Comprehensive cancer-gene panels can be used to estimate mutational load and predict clinical benefit to PD-1 blockade in clinical practice. Oncotarget 6(33):34221-34227. https://doi.org/10.18632/oncot arget.5950

Fan Y, Che X, Qu J, Hou K, Wen T, Li Z, Li C, Wang S, Xu L, Liu Y, Qu X (2019) Exosomal PD-L1 retains immunosuppressive activity and is associated with gastric cancer prognosis. Ann Surg Oncol 26(11):3745-3755. https://doi.org/10.1245/s10434-019-07431-7

Fujita Y, Yagishita S, Hagiwara K, Yoshioka Y, Kosaka N, Takeshita F, Fujiwara T, Tsuta K, Nokihara H, Tamura T, Asamura H, Kawaishi M, Kuwano K, Ochiya T (2015) The clinical relevance of the miR-197/CKS1B/STAT3-mediated PD-L1 network in chemoresistant non-small-cell lung cancer. Mol Ther 23(4):717-727. https://doi.org/10.1038/mt.2015.10

Gatalica Z, Snyder C, Maney T, Ghazalpour A, Holterman DA, Xiao N, Overberg P, Rose I, Basu GD, Vranic S, Lynch HT, Von Hoff DD, Hamid O (2014) Programmed cell death 1 (PD-1) and its ligand (PD-L1) in common cancers and their correlation with molecular cancer type. Cancer Epidemiol Biomark Prev 23(12):2965-2970. https://doi.org/10.1158/1055-9965.EPI-14-0654

Gonzalez Castro LN, Wesseling P (2021) The cIMPACT-NOW updates and their significance to current neuro-oncology practice. Neurooncol Pract 8(1):4-10. https://doi.org/10.1093/nop/npaa055

Hao C, Chen G, Zhao H, Li Y, Chen J, Zhang H, Li S, Zhao Y, Chen $\mathrm{F}$, Li W, Jiang WG (2020) PD-L1 expression in glioblastoma, the clinical and prognostic significance: a systematic literature review and meta-analysis. Front Oncol 10:1015. https://doi.org/10.3389/ fonc. 2020.01015

Hau P, Stupp R, Hegi ME (2007) MGMT methylation status: the advent of stratified therapy in glioblastoma? Dis Mark 23(1-2):97-104

Hegi ME, Diserens AC, Godard S, Dietrich PY, Regli L, Ostermann S, Otten P, Van Melle G, de Tribolet N, Stupp R (2004) Clinical trial substantiates the predictive value of O-6-methylguanine-DNA methyltransferase promoter methylation in glioblastoma patients treated with temozolomide. Clin Cancer Res 10(6):1871-1874

Hegi ME, Diserens AC, Gorlia T, Hamou MF, de Tribolet N, Weller M, Kros JM, Hainfellner JA, Mason W, Mariani L, Bromberg JE, Hau P, Mirimanoff RO, Cairncross JG, Janzer RC, Stupp R (2005) MGMT gene silencing and benefit from temozolomide in glioblastoma. N Engl J Med 352(10):997-1003. https://doi.org/ 10.1056/NEJMoa043331

Hegi ME, Liu L, Herman JG, Stupp R, Wick W, Weller M, Mehta MP, Gilbert MR (2008) Correlation of O6-methylguanine methyltransferase (MGMT) promoter methylation with clinical outcomes in glioblastoma and clinical strategies to modulate MGMT activity. J Clin Oncol 26(25):4189-4199. https://doi.org/10.1200/JCO. 2007.11.5964

Hegi ME, Sciuscio D, Murat A, Levivier M, Stupp R (2009) Epigenetic deregulation of DNA repair and its potential for therapy. Clin Cancer Res 15(16):5026-5031. https://doi.org/10.1158/10780432.CCR-08-1169

Hegi ME, Janzer RC, Lambiv WL, Gorlia T, Kouwenhoven MC, Hartmann C, von Deimling A, Martinet D, Besuchet Schmutz N, Diserens AC, Hamou MF, Bady P, Weller M, van den Bent MJ, Mason WP, Mirimanoff RO, Stupp R, Mokhtari K, Wesseling P, European Organisation for R, Treatment of Cancer Brain T, Radiation
Oncology G, National Cancer Institute of Canada Clinical Trials G (2012) Presence of an oligodendroglioma-like component in newly diagnosed glioblastoma identifies a pathogenetically heterogeneous subgroup and lacks prognostic value: central pathology review of the EORTC_26981/NCIC_CE.3 trial. Acta Neuropathol 123(6):841-852. https://doi.org/10.1007/s00401-011-0938-4

Heiland DH, Haaker G, Delev D, Mercas B, Masalha W, Heynckes S, Gabelein A, Pfeifer D, Carro MS, Weyerbrock A, Prinz M, Schnell O (2017) Comprehensive analysis of PD-L1 expression in glioblastoma multiforme. Oncotarget 8(26):42214-42225. https:// doi.org/10.18632/oncotarget.15031

Honda Y, Otsuka A, Ono S, Yamamoto Y, Seidel JA, Morita S, Hirata M, Kataoka TR, Takenouchi T, Fujii K, Kanekura T, Okubo Y, Takahashi K, Yanagi T, Hoshina D, Hata H, Abe R, Fujimura T, Funakoshi T, Yoshino K, Masuzawa M, Amoh Y, Tanaka R, Fujisawa Y, Honda T, Kabashima K (2017) Infiltration of PD1-positive cells in combination with tumor site PD-L1 expression is a positive prognostic factor in cutaneous angiosarcoma. Oncoimmunology 6(1):e1253657. https://doi.org/10.1080/21624 02X.2016.1253657

Ilie M, Khambata-Ford S, Copie-Bergman C, Huang L, Juco J, Hofman V, Hofman P (2017) Use of the 22C3 anti-PD-L1 antibody to determine PD-L1 expression in multiple automated immunohistochemistry platforms. PLoS ONE 12(8):e0183023. https://doi. org/10.1371/journal.pone.0183023

Isaacsson Velho P, Antonarakis ES (2018) PD-1/PD-L1 pathway inhibitors in advanced prostate cancer. Expert Rev Clin Pharmacol 11(5):475-486. https://doi.org/10.1080/17512433.2018.1464388

Kaina B, Christmann M, Naumann S, Roos WP (2007) MGMT: key node in the battle against genotoxicity, carcinogenicity and apoptosis induced by alkylating agents. DNA Repair 6(8):1079-1099. https://doi.org/10.1016/j.dnarep.2007.03.008

Kataoka K, Ogawa S (2016) Genetic biomarkers for PD-1/PD-L1 blockade therapy. Oncoscience 3(11-12):311-312. https://doi. org/10.18632/oncoscience.328

Kataoka K, Shiraishi Y, Takeda Y, Sakata S, Matsumoto M, Nagano S, Maeda T, Nagata Y, Kitanaka A, Mizuno S, Tanaka H, Chiba K, Ito S, Watatani Y, Kakiuchi N, Suzuki H, Yoshizato T, Yoshida $\mathrm{K}$, Sanada M, Itonaga H, Imaizumi Y, Totoki Y, Munakata W, Nakamura H, Hama N, Shide K, Kubuki Y, Hidaka T, Kameda T, Masuda K, Minato N, Kashiwase K, Izutsu K, Takaori-Kondo A, Miyazaki Y, Takahashi S, Shibata T, Kawamoto H, Akatsuka Y, Shimoda K, Takeuchi K, Seya T, Miyano S, Ogawa S (2016) Aberrant PD-L1 expression through 3'-UTR disruption in multiple cancers. Nature 534(7607):402-406. https://doi.org/10.1038/ nature 18294

Kraus TF, Greiner A, Steinmaurer M, Dietinger V, Guibourt V, Kretzschmar HA (2015a) Genetic characterization of ten-eleventranslocation methylcytosine dioxygenase alterations in human glioma. J Cancer 6(9):832-842. https://doi.org/10.7150/jca.12010

Kraus TF, Kolck G, Greiner A, Schierl K, Guibourt V, Kretzschmar HA (2015b) Loss of 5-hydroxymethylcytosine and intratumoral heterogeneity as an epigenomic hallmark of glioblastoma. Tumour Biol. https://doi.org/10.1007/s13277-015-3606-9

Kraus TFJ, Machegger L, Poppe J, Zellinger B, Dovjak E, Schlicker HU, Schwartz C, Ladisich B, Spendel M, Kral M, Reinhardt A, Winkler PA, Sotlar K (2020) Diffuse midline glioma of the cervical spinal cord with H3 K27M genotype phenotypically mimicking anaplastic ganglioglioma: a case report and review of the literature. Brain Tumor Pathol 37(3):89-94. https://doi.org/10. 1007/s10014-020-00365-Z

Li X, Wetherilt CS, Krishnamurti U, Yang J, Ma Y, Styblo TM, Meisel JL, Peng L, Siddiqui MT, Cohen C, Aneja R (2016) Stromal PD-L1 expression is associated with better disease-free survival in triple-negative breast cancer. Am J Clin Pathol 146(4):496-502. https://doi.org/10.1093/ajcp/aqw134 
Li C, Huang C, Mok TS, Zhuang W, Xu H, Miao Q, Fan X, Zhu W, Huang Y, Lin X, Jiang K, Hu D, Chen X, Huang P, Lin G (2017) Comparison of 22C3 PD-L1 expression between surgically resected specimens and paired tissue microarrays in non-small cell lung cancer. J Thorac Oncol 12(10):1536-1543. https://doi. org/10.1016/j.jtho.2017.07.015

Louis DN, Ohgaki H, Wiestler OD, Cavenee WK, Burger PC, Jouvet A, Scheithauer BW, Kleihues P (2007) The 2007 WHO classification of tumours of the central nervous system. Acta Neuropathol 114(2):97-109. https://doi.org/10.1007/s00401-007-0243-4

Louis DN, Perry A, Reifenberger G, von Deimling A, FigarellaBranger D, Cavenee WK, Ohgaki H, Wiestler OD, Kleihues P, Ellison DW (2016a) The 2016 World Health Organization classification of tumors of the central nervous system: a summary. Acta Neuropathol 131(6):803-820. https://doi.org/10.1007/ s00401-016-1545-1

Louis DN, Aldape K, Brat DJ, Capper D, Ellison DW, Hawkins C, Paulus W, Perry A, Reifenberger G, Figarella-Branger D, Wesseling P, Batchelor TT, Gregory Cairncross J, Pfister SM, Rutkowski S, Weller M, Wick W, von Deimling A (2016b) cIMPACT-NOW (the consortium to inform molecular and practical approaches to CNS tumor taxonomy): a new initiative in advancing nervous system tumor classification. Brain Pathol. https://doi.org/10.1111/ bpa. 12457

Louis DN, Wesseling P, Aldape K, Brat DJ, Capper D, Cree IA, Eberhart C, Figarella-Branger D, Fouladi M, Fuller GN, Giannini C, Haberler C, Hawkins C, Komori T, Kros JM, Ng HK, Orr BA, Park SH, Paulus W, Perry A, Pietsch T, Reifenberger G, Rosenblum M, Rous B, Sahm F, Sarkar C, Solomon DA, Tabori U, van den Bent MJ, von Deimling A, Weller M, White VA, Ellison DW (2020) cIMPACT-NOW update 6: new entity and diagnostic principle recommendations of the cIMPACT-Utrecht meeting on future CNS tumor classification and grading. Brain Pathol 30(4):844-856. https://doi.org/10.1111/bpa.12832

Nduom EK, Wei J, Yaghi NK, Huang N, Kong LY, Gabrusiewicz K, Ling X, Zhou S, Ivan C, Chen JQ, Burks JK, Fuller GN, Calin GA, Conrad CA, Creasy C, Ritthipichai K, Radvanyi L, Heimberger AB (2016) PD-L1 expression and prognostic impact in glioblastoma. Neuro Oncol 18(2):195-205. https://doi.org/10. 1093/neuonc/nov172
Neuman T, London M, Kania-Almog J, Litvin A, Zohar Y, Fridel L, Sandbank J, Barshak I, Vainer GW (2016) a harmonization study for the use of 22C3 PD-L1 immunohistochemical staining on Ventana's platform. J Thorac Oncol 11(11):1863-1868. https://doi. org/10.1016/j.jtho.2016.08.146

Ohaegbulam KC, Assal A, Lazar-Molnar E, Yao Y, Zang X (2015) Human cancer immunotherapy with antibodies to the PD-1 and PD-L1 pathway. Trends Mol Med 21(1):24-33. https://doi.org/10. 1016/j.molmed.2014.10.009

Reck M, Rodriguez-Abreu D, Robinson AG, Hui R, Csoszi T, Fulop A, Gottfried M, Peled N, Tafreshi A, Cuffe S, O'Brien M, Rao S, Hotta K, Leiby MA, Lubiniecki GM, Shentu Y, Rangwala R, Brahmer JR, Investigators K (2016) Pembrolizumab versus chemotherapy for PD-L1-positive non-small-cell lung cancer. N Engl J Med 375(19):1823-1833. https://doi.org/10.1056/NEJMo a1606774

Roge R, Vyberg M, Nielsen S (2017) Accurate PD-L1 protocols for non-small cell lung cancer can be developed for automated staining platforms with Clone 22C3. Appl Immunohistochem Mol Morphol 25(6):381-385. https://doi.org/10.1097/PAI.0000000000 000534

Said EA, Dupuy FP, Trautmann L, Zhang Y, Shi Y, El-Far M, Hill BJ, Noto A, Ancuta P, Peretz Y, Fonseca SG, Van Grevenynghe J, Boulassel MR, Bruneau J, Shoukry NH, Routy JP, Douek DC, Haddad EK, Sekaly RP (2010) Programmed death-1-induced interleukin-10 production by monocytes impairs CD4+ T cell activation during HIV infection. Nat Med 16(4):452-459. https:// doi.org/10.1038/nm.2106

Sun C, Mezzadra R, Schumacher TN (2018) Regulation and function of the PD-L1 checkpoint. Immunity 48(3):434-452. https://doi. org/10.1016/j.immuni.2018.03.014

Publisher's Note Springer Nature remains neutral with regard to jurisdictional claims in published maps and institutional affiliations. 